\title{
A endogamia da Comunicação: redes de colaboração na CSAI
}

\section{Endogamy in Communication Studies: scholarly collaboration in CSAI}

\author{
Marco T. Bastos \\ Pesquisador associado e pós-doutorando na Universidade da Califórnia em Davis. É pós-doutor, doutor e mestre em Ciências da \\ Comunicação pela Universidade de São Paulo (USP).
}

<mtabastos@gmail.com>

\section{Gabriela Zago}

Professora da Universidade Federal de Pelotas (UFPel). É doutora e mestre em Ciências da Comunicação e Informação pela Universidade Federal do Rio Grande do Sul (UFRGS).

<gabrielaz@gmail.com>

\section{Raquel Recuero}

Professora da Universidade Católica de Pelotas. É doutora e mestre em Ciências da Comunicação e Informação pela Universidade Federal do Rio Grande do Sul (UFRGS).

$<$ raquelrecuero@gmail.com>

\section{RESUMO}

O presente artigo analisa e discute as redes de colaboração na área de Ciências Sociais Aplicadas I. Os registros de coautoria e colaborações foram identificados e extraídos da base de dados Lattes do CNPq e análise de redes sociais foi empregada para oferecer um panorama da área, e mais especificamente, dos grupos de colaboração da subárea Comunicação. Os resultados da análise apontam para comunidades formadas pela combinação de diferentes critérios, mas sobretudo em função das instituições de ensino superior, e apenas marginalmente em função dos temas de pesquisa ou regiões geográficas. Além disso, os resultados também indicam a presença consideravelmente mais expressiva de redes colaboração na subárea Ciências da Informação em comparação com a subárea Comunicação.

Palavras-chave: Plataforma Lattes. Colaboração Acadêmica. Redes Sociais.

\section{Introdução ${ }^{1}$}

\section{A incidência de colaborações acadêmicas entre pesquisadores ocorre}

1 Agradecimentos especiais para Luciano Antonio Digiampietri e pesquisadores associados que gentilmente forneceram os IDs dos currículos a serem minerados, e a Ricardo Matsumura Araújo, que fez a extração dos currículos Lattes. 
em decorrência de diferentes critérios que são difíceis de quantificar. A relativa integração de cada área, a proximidade geográfica e a presença de fatores institucionais e departamentais são fatores que influenciam a ocorrência de colaborações acadêmicas conforme detalhado nas pesquisas da área (Barabási e outros, 2002; Moody, 2004; Newman, 2004). Pesquisadores de uma mesma instituição podem produzir pesquisas em conjunto (tanto entre colegas como entre orientadores e orientandos), da mesma forma que pode haver colaboração entre pesquisadores de instituições diferentes que pesquisam temas semelhantes.

Nesse sentido, estudar as colaborações dentro de uma área pode ajudar a identificar padrões e estruturas associados a um determinado campo de pesquisa. Informações detalhadas sobre pesquisadores com maior número de coautores, pesquisadores mais centrais, e comunidades específicas de coautores podem ser identificadas por meio da análise de redes sociais e métodos oriundos da sociometria, mormente empregados para identificar redes de colaboração (Leydesdorff, 2004a; 2004b). Por meio desse tipo de análise, é possível identificar funções específicas desempenhadas por pesquisadores ou grupos de pesquisadores em área e subáreas de pesquisa (Bastos, 2015), assim como identificar problemas estruturais e apontar soluções possíveis para as políticas da área.

Com base nesse cenário, este trabalho analisa a coautoria entre pesquisadores da área de Ciências Sociais Aplicadas I no Brasil por meio dos currículos de doutores extraídos do banco de dados da plataforma Lattes, uma plataforma unificada que inclui informações detalhadas sobre o vínculo institucional, redes de colaboração, área de atuação e produtividade acadêmica de pesquisadores brasileiros. Em função da ampla cobertura desse banco de dados, a Plataforma Lattes tem sido explorada por diversos pesquisadores interessados nos indicadores e na estrutura das redes de colaboração científica no Brasil (Balancieri e outros, 2005).

Neste contexto, o presente trabalho avalia a hipótese de que a área de Ciências Sociais Aplicadas I no Brasil - que reúne pesquisadores das áreas de Comunicação, Ciências da Informação e Museologia - seria separada e estruturada em função de grupos de pesquisadores associados a determinadas instituições de ensino e a grupos de indivíduos dedicados à pesquisa em subtemas da área. Os resultados dessa análise apontam para grupos constituídos de formas diversas: de um lado, a análise indica a existência de grupos de pesquisa reunidos em função de temas de pesquisa; por outro lado, os grupos 
de pesquisa também são formados em função da instituição de ensino superior onde os pesquisadores atuam.

Naturalmente, a base de dados também identifica a existência de grupos de pesquisa interligados por ambos os critérios (tema e instituição) e em diversas ocorrências é possível inferir a importância da proximidade geográfica entre pesquisadores (independente dos vínculos institucionais). Além disso, a análise identifica grupos híbridos entre as subáreas das Ciências Sociais Aplicadas I, embora a maior parte da rede seja restrita à subárea de Ciências da Informação. Por fim, os resultados também diagnosticam o relativo isolamento da área de Comunicação em função dos fracos indicadores de colaboração acadêmica, não obstante o maior número de programas de pós-graduação no país dedicados à Comunicação em comparação com as Ciências da Informação.

\section{CSAl e as redes de colaboração acadêmica}

As subáreas ${ }^{2}$ de Comunicação e Ciências da Informação estão vinculadas na classificação das áreas do conhecimento empregadas pelas agências de fomento à pesquisa no Brasil conforme detalhado no documento CAPES da área intitulado "A área Ciências Sociais Aplicadas I". Além das Ciências da Informação e da Comunicação, a CSAI também inclui a Museologia e integra a grande área Ciências Sociais Aplicadas (CAPES, 2013, p. 1). De acordo com o documento da CAPES, a Comunicação é a subárea mais expressiva com um total de 63 programas de pós-graduação, seguida pelas Ciências da Informação (23 PPGs) e pela Museologia (3 PPGs), cujo desenvolvimento como área de pesquisa independente difere substantivamente da Comunicação e das Ciências da Informação.

De fato, comunicação e informação compartilham um processo de maturação institucional análogo, uma vez que a pesquisa nas áreas de Comunicação e em Ciências da Informação e Biblioteconomia data da segunda metade da década de 1970 e início da década de 1980, quando surgiram os primeiros programas de mestrado e foram consolidados os primeiros departamentos e centros de pesquisa em comunicação (Bastos, 2012) e Ciências da Informação e Documentação (Figueiredo, 1978; Ortega, 2009). Não obstante os departamentos de Biblioteconomia tenham se tornaram autônomos nesse período, em diversas ocasiões Biblioteconomia e Comunicação permaneceram vinculados institucionalmente (Stumpf e Weber, 2003). A afinidade entre as duas

2 Nesse artigo nos referimos às áreas de Comunicação e Ciências da Informação como "subáreas" em função da nomenclatura empregada pela comissão das Ciências Sociais Aplicadas I. 
subáreas se verifica em diversos contextos universitários e uma aproximação efetiva entre as duas correntes de pesquisa foi planejada e realizada em contextos institucionais em que as duas subáreas estão compreendidas dentro de um mesmo programa de pós-graduação (Stumpf e Weber, 2003).

Contudo, a eventual proximidade institucional não produziu impacto nos indicadores de colaboração acadêmica. Segundo Balancieri e outros (2005), "a colaboração científica pode ser um empreendimento cooperativo que envolve metas comuns, esforço coordenado e resultados ou produtos (trabalhos científicos) com responsabilidade e mérito compartilhados". De todo modo, as redes de colaborações acadêmicas constituem um objeto de pesquisa com extensa bibliografia cuja natureza e escopo foram detalhados nos trabalhos de Wagner e Leydesdorff (2005) e Cechinel (2013). Mais recentemente, a colaboração científica também foi estudada com base nos sites de redes sociais voltados para o público acadêmico (Bullinger e outros, 2010; Gewin, 2010), espaços em que a associação é mormente voluntária. A própria Plataforma Lattes, objeto deste trabalho, descrita por Lane (2010) como um exemplo a ser seguido na padronização dos dados sobre pesquisadores de um determinado país, também já foi objeto de estudos semelhantes (Digiampietri e outros, 2014; Mena-Chalco e outros, 2014).

Historicamente, as ciências naturais tendem a possuir mais coautorias do que as ciências sociais. O relativo isolamento dos pesquisadores das ciências humanas e sociais é possivelmente relacionado com as características da pesquisa na área, que privilegia trabalhos teóricos e a imersão individual do pesquisador em um tema específico. Para Katz e Martin (1997, citado por Balancieri e outros, 2005), "em geral trabalhos teóricos produzem artigos com poucos coautores em comparação a trabalhos experimentais". Em contraposição a esse diagnóstico, o documento da Área de 2013 referente às Ciências Sociais Aplicadas I (CAPES, 2013) enfatiza a importância da integração e cooperação entre instituições. Esse mesmo critério de avaliação também já se encontrava presente no relatório referente ao triênio anterior (CAPES, 2009), ainda que a ênfase na coautoria entre orientandos e orientadores como critério de avaliação do corpo discente apareça apenas no documento de 2013. De todo modo, esse breve histórico indica que a coautoria vem sendo paulatinamente enfatizada na CSAI.

\section{Coautoria e análise de redes sociais}

A relação entre redes de coautoria e análise de redes sociais já foi abordada por inúmeros pesquisadores e um levantamento detalhado se encontra 
presente nos trabalhos de Maia e Caregnato (2008), que empregaram análise de redes sociais para o estudo de redes de colaboração científica entre professores do PPG em Epidemiologia da UFPel, e Martins e Ferreira (2014), que realizaram um estudo das redes de coautoria na área de Comunicação a partir de dados extraídos do portal Univerciência. Além de identificar elementos estruturais das redes de coautoria, esse último estudo também identifica a dinâmica temporal de múltiplos indicadores da área de Ciências da Comunicação. Outras pesquisas trabalharam as relações de citação em revistas (Romancini, 2004) e congressos (Primo e outros, 2008) da subárea de Comunicação.

A análise das redes sociais, com isso, conforma um método estabelecido com ampla bibliografia (Otte e Rousseau, 2002) dedicada ao estudo das redes de colaboração. Newman (2001) utilizou bancos de dados da medicina, da física e da ciência da computação para estudar as redes de colaboração acadêmica e Da Silva e outros (2012) estudaram as redes de citação a partir dos trabalhos publicados em um congresso da área de Ciências da Informação no Brasil. Com isso, a análise de redes sociais constitui um método privilegiado para a compreensão das redes de colaboração extraídas de bancos de dados, uma vez que permite a análise computacional e o diagnóstico das diferentes estruturas e desenvolvimentos específicos das áreas do saber acadêmico (Digiampietri e outros, 2012).

Uma rede social é formada pela associação entre nós ou atores e suas conexões ou arestas (Recuero, 2009). De maneira simplificada, a Análise de Redes Sociais (ARS) constitui um conjunto de métricas e técnicas de pesquisa utilizadas para descrever a relação entre atores e suas conexões estabelecida em uma rede social (Wasserman e Faust, 1994; Degenne e Forsé, 1999; Carrington e outros, 2005). A ARS permite o estudo da estrutura dos grupos sociais em contraposição ao estudo isolado dos atores sociais. A unidade de análise, com isso, é relacional em contraposição aos múltiplos nós individuais que compõem a rede. Uma rede, por sua vez, consiste em um conjunto de atores e relações entre os membros de um grupo. Um grupo, por sua vez, é um "conjunto de todos os atores cujas relações são analisadas" (Wasserman e Faust, 1994, p. 19) ${ }^{3}$, de modo que um subgrupo sempre remete a um recorte maior de atores e conexões. Diversas métricas podem ser utilizadas para o estudo das redes sociais, seus grupos, subgrupos e nós. Dentre essas métricas, destacamos a seguir algumas medidas de especial interesse para o presente trabalho.

3 Tradução livre de "a group is the collection of all actors on which ties are to be measured". 
A primeira métrica considerada é a modularidade. A modularidade identifica os grupos subjacentes à estrutura da rede. Ela é calculada tendo por base a separação dos nós da rede em módulos (ou comunidades). Essas comunidades, por sua vez, são definidas como grupos de nós densamente interligados entre si e escassamente conectados com o restante da rede. Com isso, redes com alta modularidade tendem a ter conexões densas entre os nós de cada comunidade e poucas conexões com nós de outras comunidades (ou módulos). Em razão do método otimizado de cálculo para a modularidade, ela é frequentemente empregada para a detecção de estrutura de comunidade em redes sociais, e no presente trabalho a modularidade é adotada para identificar grupos de pesquisadores presentes nas redes de coautoria extraídas da Plataforma Lattes.

Os nós são estudados em função de sua centralidade na estrutura geral da rede e em cada um dos grupos em que estão inseridos. Freeman (1978) aponta três métricas para analisar a centralidade dos nós em uma rede de comunicação: o grau de conexão, o grau de intermediação (ou betweeness) e o grau de proximidade. O grau de conexão identifica o nó com maior centralidade com base no número absoluto de conexões. Os nós periféricos, em oposição aos nós centrais, apresentam baixo grau de conexão, não obstante operem funções críticas na rede. $O$ grau de conexão refere-se apenas à frequência ou intensidade da conexão entre dois nós. O grau de conexão é uma medida numérica, normalmente referida como o somatório de todas as conexões existentes de e para N. Em redes direcionais, o grau pode ser desdobrado em conexões recebidas (indegree) e conexões enviadas (outdegree), outro ponto importante para a análise que detalharemos a seguir.

O grau de intermediação (ou betweeness) é uma medida de centralidade que indica o número de vezes que um nó serve de ponte para outros nós ou grupos de nós. O grau de intermediação identifica como central os nós que oferecem atalhos ou que fazem a ligação entre os demais nós da rede, conectando com isso outros nós de maneira mais eficiente. Para Freeman (1978, p. 221), "o ponto que se situa entre os caminhos da comunicação pode potencialmente controlar a comunicação".4 O grau de proximidade (closeness), por fim, indica o quão próximo um nó está dos demais da rede. Assim, a terceira forma de medir a centralidade de um nó empregada nesse trabalho é o grau de proximidade, que indica a medida na qual um nó está próximo dos demais nós

4 Tradução livre de "a point that falls on the communication paths between other points exhibits a potential for control of their communication". 
da rede. Essa métrica de centralidade também está relacionada com o controle da comunicação, pois "um ponto é tido como central na medida em que tem condições de evitar o controle exercido por outros nós" (Freeman, 1978, p. 224). ${ }^{5}$

\section{Procedimentos metodológicos}

Os dados foram coletados a partir do currículo Lattes de pesquisadores brasileiros da área de CSAI. Os arquivos XML (eXtensible Markup Language) identificados como sendo de pesquisadores da área de CSAI com titulação de doutor foram extraídos diretamente do banco de dados do Lattes a partir de um script baseado no trabalho desenvolvido por Digiampietri e outros (2012), cuja pesquisa seminal data de 2012. Com isso, o conjunto de dados detalhados no presente trabalho refere-se apenas aos pesquisadores que se doutoraram até 2012. Após a identificação dos currículos de pesquisadores da área de CSAI, foram extraídas informações sobre as relações de colaboração, incluindo coautorias em artigos científicos, capítulos de livro, participação em bancas, organização de produtos e demais indicadores de produção. A Plataforma Lattes permite a identificação de coautores a partir do estabelecimento de um link direcional entre currículos Lattes. Assim, se um pesquisador identifica outro pesquisador como coautor ou colaborador em seu currículo Lattes, a ferramenta estabelece um link entre os currículos que pode ser extraído da base de dados XML.

Com isso, os dados analisados nesse trabalho incluem os currículos de pesquisadores que se doutoraram até 2012 e que identificaram, em seus currículos Lattes, sua área como sendo Ciências Sociais Aplicadas I. Criamos uma conexão direcional entre o currículo Lattes de cada pesquisador cujas colaborações aparecem listadas no currículo do autor (código: NRO-ID-CNPQ). Uma vez que a criação de hyperlinks entre currículos requer a autorização por ambos os pesquisadores, esse método para extração da rede privilegia pesquisadores com rotinas institucionais comuns, e o resultado das análises deve refletir a incidência de colaborações intradepartamentais. Optamos por manter a direcionalidade entre os currículos, não obstante redes de colaboração não sejam direcionais, para dirimir o inchaço de citações por parte de pesquisadores que não têm o hyperlink validado pela contraparte. A justificativa para esse método é diminuir o impacto de usuários mais familiarizados com a Plataforma Lattes.

5 Tradução livre de "a point is viewed as central to the extent that it can avoid the control potential of others". 
A partir desses currículos foram extraídos os links que representavam coautorias em artigos acadêmicos e colaborações em geral (que inclui as coautorias). Após um processo de limpeza e organização dos dados, em que foram descartados currículos com problemas de preenchimento, foram identificados 2.543 currículos e 3.519 conexões entre currículos. Esse conjunto de dados final indica que muitos pesquisadores (representados pelos currículos) não apresentam quaisquer colaborações ou exibem baixíssimos índices de colaborações listadas no currículo Lattes. De fato, apenas $65 \%$ dos currículos apresentam colaborações (1.673) e menos da metade (48\%) apresenta duas ou mais colaborações acadêmicas (1.243 de 3.112 conexões). De modo geral, o número de colaborações identificadas no Lattes é baixo (média de duas colaborações por currículo) e o número máximo de conexões observadas em todos os currículos foi 81.

De maneira resumida, as redes que detalhamos a seguir só reconhecem uma relação entre pesquisadores que conectaram seus currículos; inclui apenas pesquisadores na área de CSAI com titulação mínima de doutor, e está restrita aos currículos de pesquisadores que se doutoraram até 2012 (a produção, no entanto, está atualizada até 2014). Também analisamos qualitativamente o currículo dos pesquisadores com maior número de colaborações (grau 10 ou superior), que corresponde ao extrato de $6 \%$ (160 nós) dos currículos com maior número de conexões (total de 703 conexões ou 20\%). Assim como já detalhado na bibliografia da área (Barabási e outros, 2002), as colaborações por currículo seguem uma distribuição power law, ou seja, uma curva logarítmica com alta concentração de conexões em um pequeno número de nós. Dentro desse grupo, a média de colaborações identificadas é de 4,4 por autor. Utilizamos esse grupo de pesquisadores ativos para realizar a análise qualitativa que identificou as principais subáreas de atuação. Nos casos em que mais de uma área de atuação foi identificada pelos pesquisadores, consideramos apenas aquela de maior incidência no currículo.

As análisesque descrevemos a seguirse referemàspublicações acadêmicas dos pesquisadores (artigos, livros e capítulos de livros) e colaborações em geral, constituindo no todo uma rede de 1.148 nós (currículos) e 2095 arestas (colaborações). É importante salientar que foram considerados aqui os nós com pelo menos uma coautoria dentro da área de CSAI. A média, portanto, é de 1,82 coautorias por currículo. $O$ número máximo de coautorias observado (grau) é de 34. Também analisamos qualitativamente os currículos dos pesquisadores para identificar as comunidades e os principais coautores e suas áreas de atuação e formação. Os dados foram analisados utilizando o programa de visualização 
de dados relacionais Gephi. Uma vez que o objetivo do trabalho é detalhar as colaborações entre subáreas e entre grupos distintos, optamos por privilegiar as métricas de centralidade betweenness (centralidade de intermediação), que busca identificar as pontes entre os vários grupos, e grau de conexão (identificando os nós com maior número de conexões). Embora a base de dados Lattes seja de acesso público, foram removidas as referências a pesquisadores individuais de modo a salientar apenas a ocorrência de programas e centros de pesquisa.

\section{Resultados}

\section{Colaborações gerais}

Analisaremos em princípio todas as colaborações listadas no currículo Lattes dos pesquisadores, incluindo com isso não apenas coautorias, mas bancas de avaliação e projetos de pesquisa. As colaborações da área aparecem centralizadas em dois grandes hubs que incluem um número maior de nós pertencentes às subáreas Ciências da Informação e Comunicação. A área de Museologia é praticamente inexiste no grafo apresentado na Figura 1, que detalha a proeminência das Ciências da Informação em comparação com as demais subáreas, não obstante o maior número de programas e de pesquisadores vinculados à subárea da Comunicação (CAPES, 2013).

Figura 1 - Rede de colaboração entre pesquisadores com maior número de conexões $(>10)$.

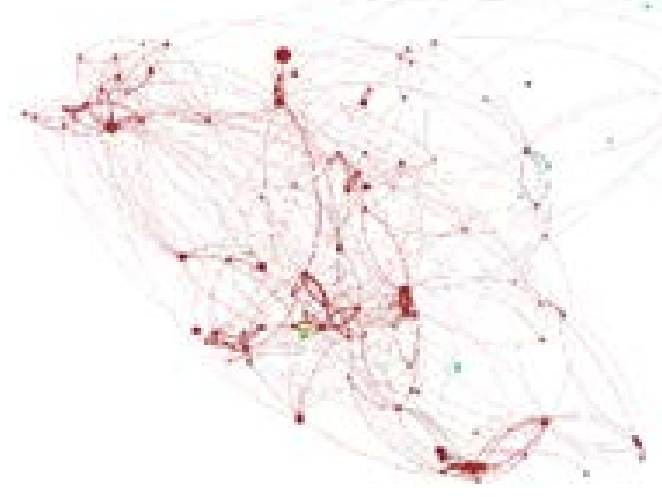

Fonte: Os autores

Ciências da Informação em vermelho, Comunicação em azul e Museologia em verde. 
A Figura 1 mostra a rede formada pelos pesquisadores com maior número de colaborações (mais de dez colaborações identificadas) e indica o número de pesquisadores com coautoria tendo por base apenas o número de colaborações (grau) e a partição em grupos ou comunidades (modularidade). O cluster da Ciências da Informação compreende 114 nós e 593 conexões, uma média de 5,2 conexões por pesquisador (em vermelho). Já o cluster de pesquisadores filiados à Comunicação compreende apenas 70 nós e 112 conexões, com uma média de apenas 1,6 conexões por pesquisador (em azul).

É importante observar o baixo número de pontes existentes entre as duas subáreas, o que é um indicativo do relativo isolamento e da baixa interconexão entre as subáreas. Com poucas exceções, a maioria dos nós que conectam diferentes grupos se encontram dentro das próprias comunidades (ou subáreas), mas não entre grupos das Ciências da Informação e da Comunicação. Uma exceção é o Programa de Pós Graduação em Comunicação e Informação da UFRGS, que constrói as principais pontes entre os pesquisadores com maior número de colaborações da área. De modo geral, o número de colaborações entre as subáreas de CSAI é inexpressivo.

\section{Coautorias na CSAI}

Analisaremos agora apenas as coautorias em publicações acadêmicas. A maior parte das coautorias reportadas se concentra entre pesquisadores da mesma subárea, com ênfase para as Ciências da Informação, onde essas práticas se encontram mais presentes em comparação com a Comunicação. Não obstante a definição de coautoria no Lattes seja extensa e inclua livros, congressos e artigos científicos, a relativa ausência de indicadores expressivos de coautoria oferece um diagnóstico sobre as práticas de cooperação na área. As relações de coautoria na área de Comunicação no Brasil são particularmente anódinas, e as poucas conexões identificadas ocorrem predominantemente entre pesquisadores do mesmo programa de pós-graduação. O gráfico da Figura 2 utiliza cores distintas para identificar os módulos (comunidades) da rede e destaca a endogamia que caracteriza a pesquisa na área, com leiaute concêntrico que facilita a identificação das comunidades e enfatiza o relativo isolamento de cada grupo com relação aos demais. 
- Figura 2 - Isolamento dos grupos de colaboração acadêmica e a endogamia da pesquisa na área de CSAI

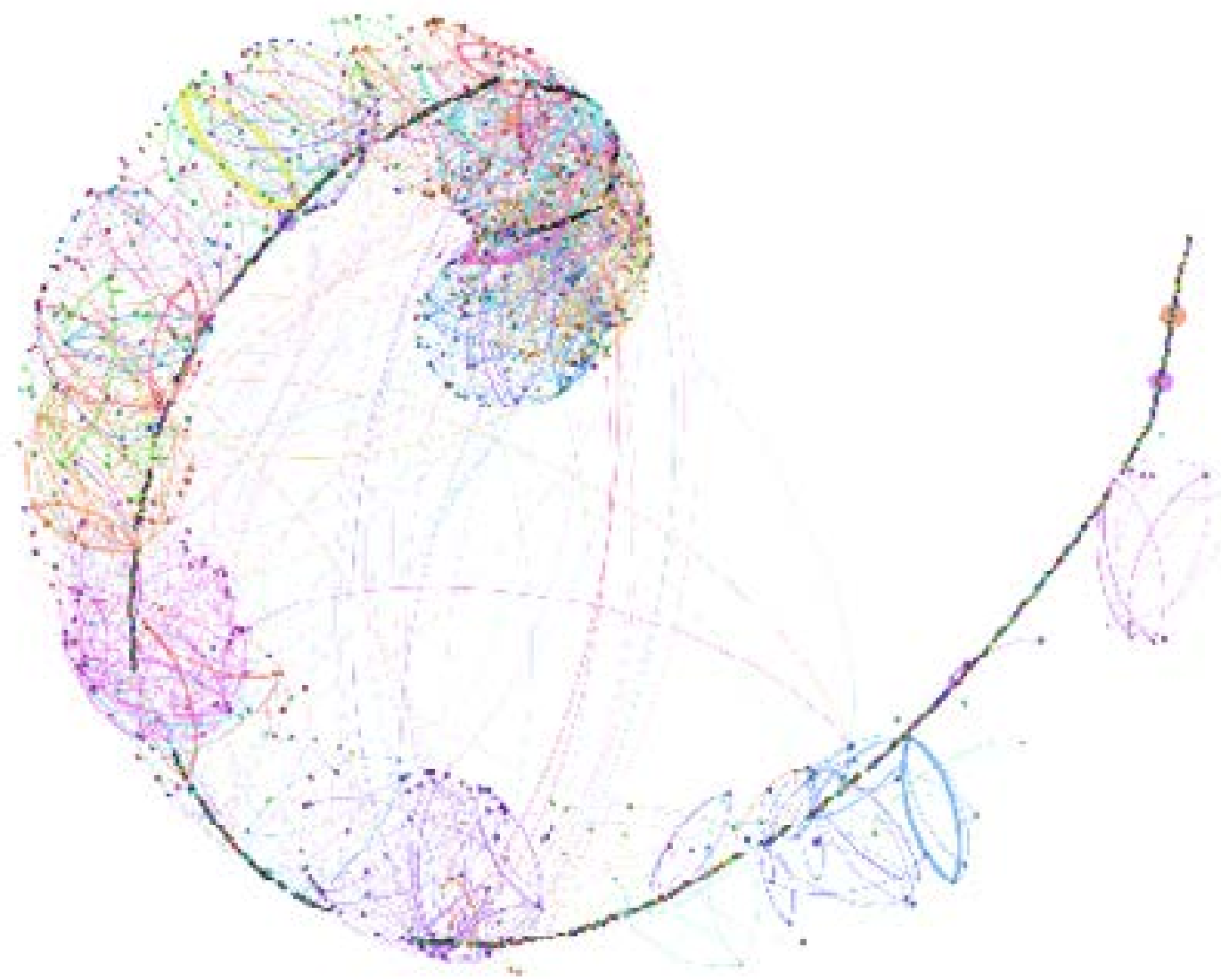

Fonte: Os autores

Para a análise de coautorias consideramos apenas as coautorias identificadas no currículo Lattes dos pesquisadores pertencentes à CSAI. O grafo da rede de coautorias em publicações da área da Comunicação no Brasil permite perceber a presença de vários grupos distintos (representados pelas cores), mas interligados entre si e com escassa conexão intergrupal. De maneira simplificada, essa dinâmica pode ser descrita como uma sequência de redes small world isoladas, uma vez que os nós de cada grupo apresentam conexões entre si e uma distância média relativamente baixa, mas também apresentam isolamento considerável em função da relativa inexistência de pontes entre os grupos. O grafo apresentado na Figura 2 indica a multiplicidade de grupos que permanecem ilhados e com baixo nível de colaboração interdepartamental ou interinstitucional.

De maneira simplificada, a Figura 2 apresenta o diagnóstico de uma área segmentada em diversas paróquias descoladas de qualquer diocese. 
Detalhes dessa fragmentação são apresentados no grafo da Figura 3 com os grupos de pesquisadores na área. Cada cor se refere a um agrupamento de nós (módulo ou comunidade) totalizando 1.301 comunidades. Conforme descrito anteriormente, cada módulo representa um conjunto de pesquisadores mais conectados entre si do que a outros grupos. Um mesmo pesquisador pode estar conectado a mais de um grupo, mas será incluído em apenas uma comunidade (aquela em que possui maior número de conexões). O tamanho do nó representa o grau de conexão do pesquisador. Quanto maior nó, maior o número de links associados ao pesquisador por outros currículos Lattes.

Figura 3 - Fragmentação dos grupos de pesquisadores na área de CSAI. Total de 1.301 comunidades identificadas com cores diferentes.

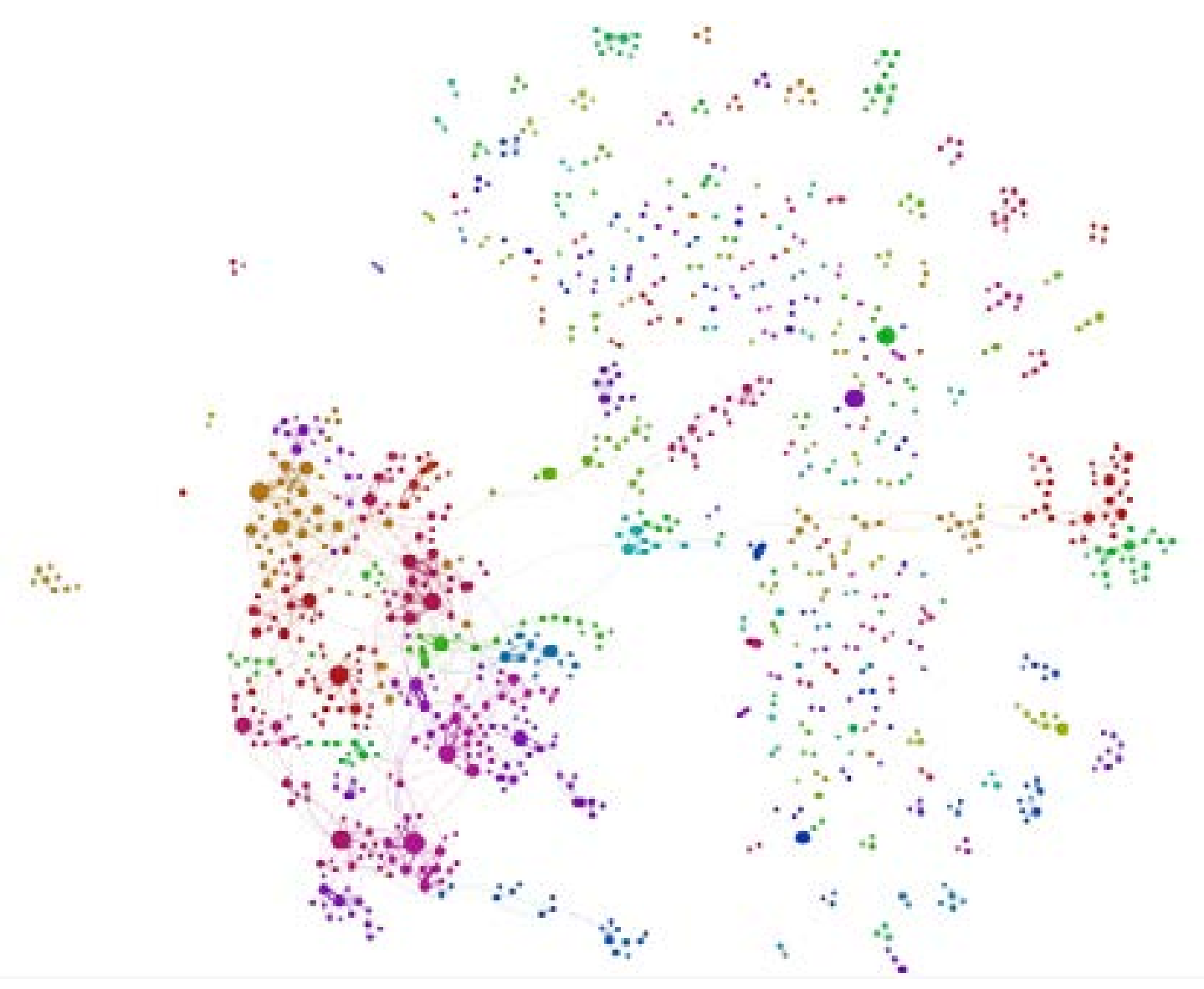

Fonte: Os autores

Uma métrica para identificar a baixa conexão entre as comunidades é a identificação dos componentes da rede. De fato, há 1.285 subgrupos de autores fracamente conectados (weakly connected components). A clusterização é bastante baixa $(0,008)$ e a distância entre os autores é particularmente longa, 
com uma média de 8,545 saltos entre um autor e outro, quando a média em outras áreas é menos da metade desse valor (Newman, 2004). Contudo, a interconexão entre autores de uma mesma comunidade é considerável. Os autores comumente compartilham os mesmos coautores, e a patente endogamia da rede é expressa pelo alto índice de embeddedness $(0,639)$. De fato, o índice de coautorias é patentemente baixo, com uma média de menos de um artigo em parceria com outros autores para cada nó da rede, incluindo nessa somatória toda a área de CSAI. Há apenas 226 autores com pelo menos cinco coautorias, intra ou interdepartamentais. A Figura 4 representa o grafo de coautorias na área CSAI, mas inclui apenas autores com um mínimo de cinco coautorias.

\section{- Figura 4 - Coautorias na área CSAI entre autores com um mínimo de cinco coautorias.}

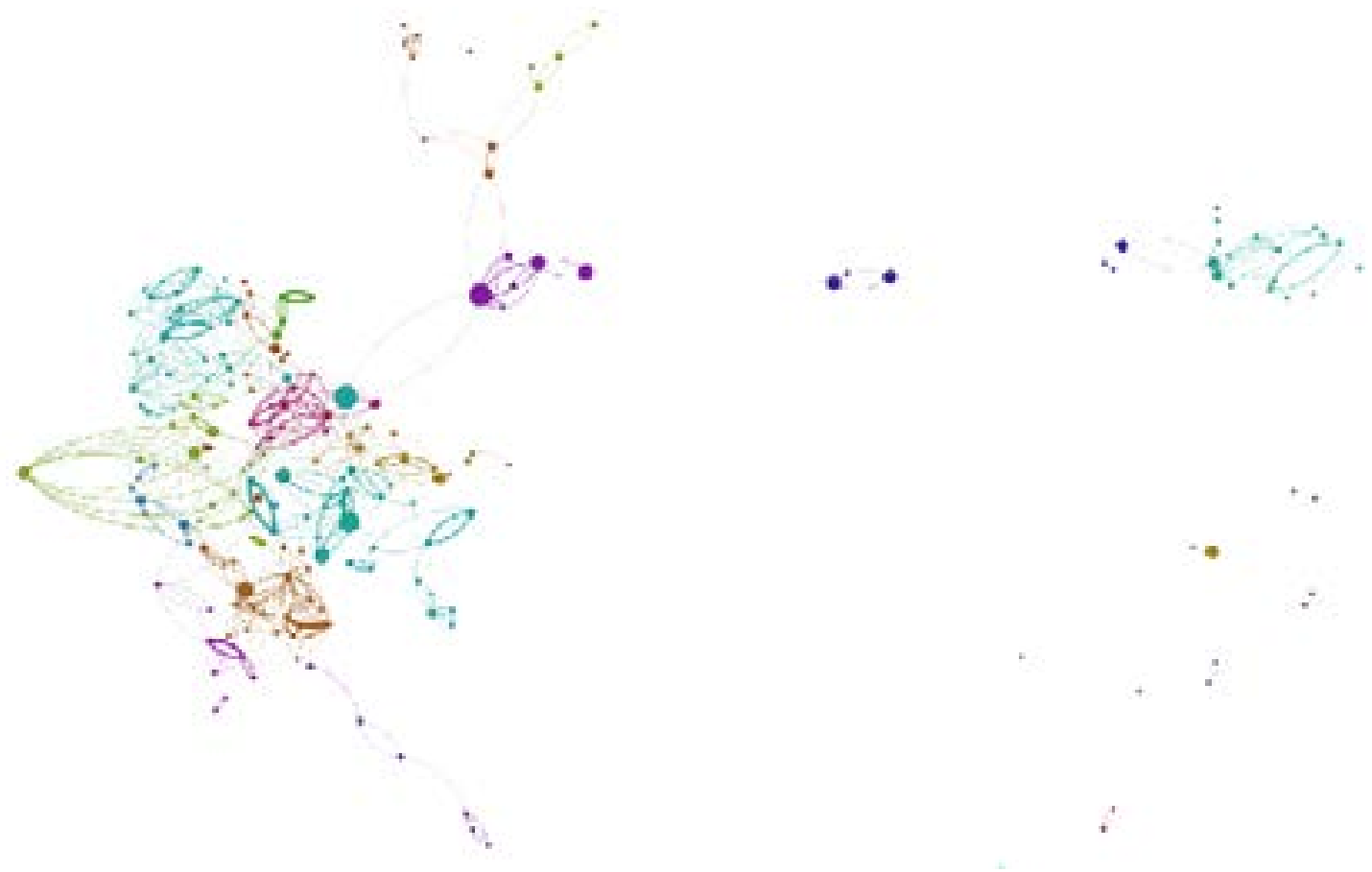

Fonte: Os autores

Embora pesquisadores da área de Comunicação predominem na CSAI, isso não necessariamente se reflete na proporção de coautorias. Ao identificar a área de atuação dos usuários com indegree maior que cinco (ou seja, pesquisadores mencionados como coautor em outros currículos em pelo menos cinco ocasiões), apenas 21 de um total de 90 pesquisadores (o equivalente a 
23\%) listaram a Comunicação como sua primeira área de atuação. É importante observar, por exemplo, que o principal componente do grafo inclui apenas pesquisadores das Ciências da Informação, enquanto a Comunicação aparece representada apenas em pequenos grupos conectados por pontes a outros pesquisadores da Comunicação. Esse componente central com pesquisadores das Ciências da Informação compreende 546 nós e 1.403 conexões (uma média de 2,5 coautorias identificadas por pesquisador).

\section{- Figura 5 - Pesquisadores com maior número de conexões, mormente vinculados às Ciências da Informação.}

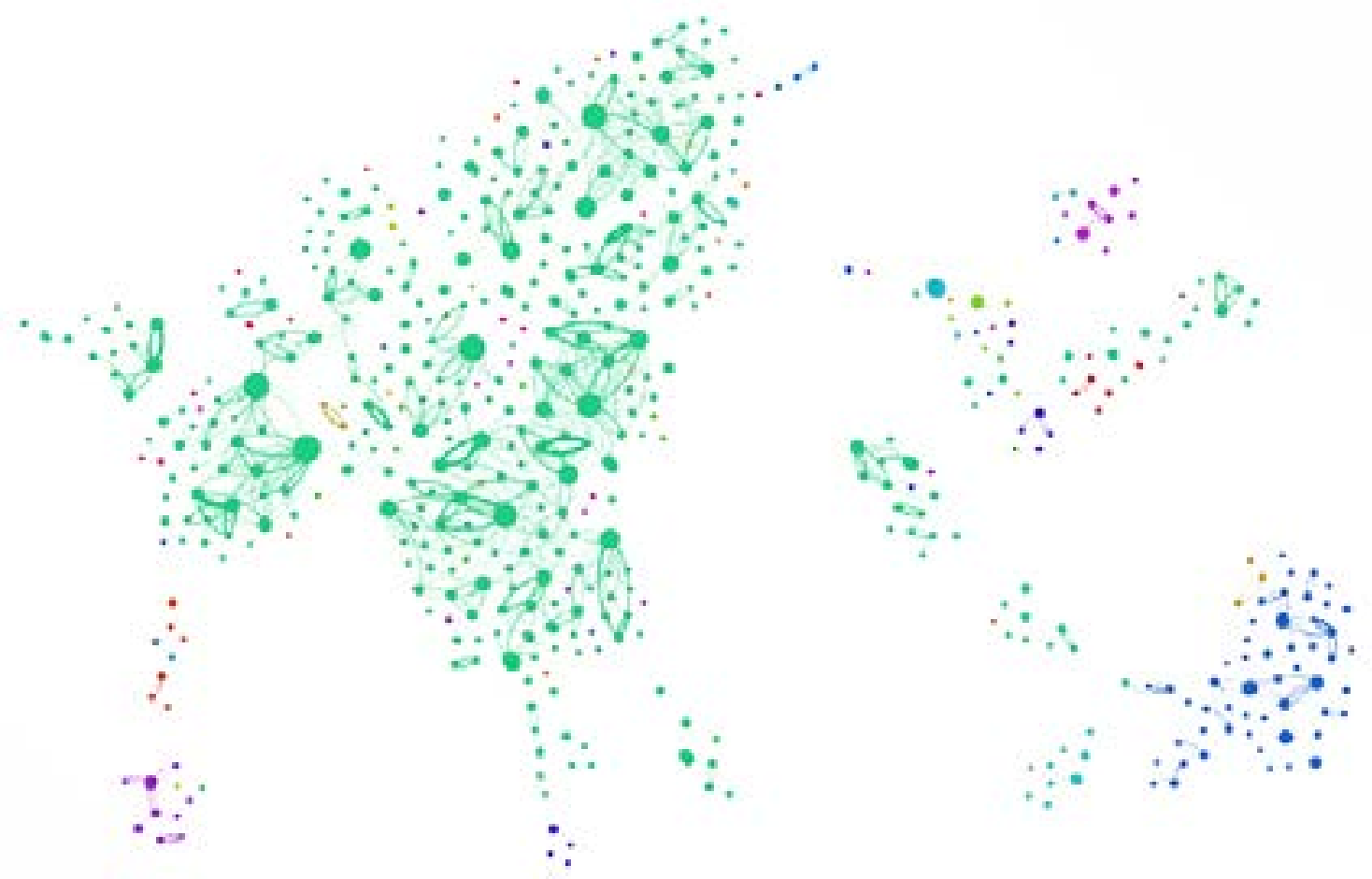

Fonte: Os autores

A Figura 5 exibe em detalhe o núcleo mais fortemente conectado com pesquisadores associados principalmente às Ciências da Informação. As demais cores indicam pesquisadores associados à Comunicação. As pontes (pesquisadores com maior grau intermediação) se localizam majoritariamente em pesquisadores vinculados a programas interdisciplinares de Ciências da Informação e Comunicação ou que desenvolvem pesquisas de cunho interdisciplinar. Em resumo, os grafos indicam que a cooperação acadêmica é uma prática mais frequente nas Ciências da Informação. Uma explicação possível para essa disparidade é a maior incidência de pesquisas empíricas nas Ciências da Informação. Estudos anteriores identificaram maior incidência de coautorias 
na área de Sociologia em grupos de pesquisadores que trabalham com métodos quantitativos (Moody, 2004). Além disso, dentre os 20 pesquisadores com maior número de coautorias identificadas no Lattes, apenas um pesquisador tem vínculo com a subárea da Comunicação.

\section{Comunidades de coautores nas CSAI}

$\mathrm{O}$ algoritmo de modularidade permitiu a identificação das principais comunidades de pesquisadores na área de Ciências Sociais Aplicadas I no Brasil. A seguir, analisamos qualitativamente a composição das 10 maiores comunidades. A maior comunidade congrega 59 pesquisadores e a menor delas 23. Em cada um desses grupos, buscou-se identificar os nós centrais, ou seja, os nós que receberam mais conexões (mencionados com maior frequência) em outros currículos (grau de conexão indegree). Também buscamos identificar os nós com maior grau de intermediação (betweeness), pois essa métrica identifica pesquisadores que desempenham um papel importante ao servir de ponte entre membros desconectados da rede.

Desses 10 grupos, sete são compostos de pesquisadores das Ciências da Informação e em apenas três grupos há pesquisadores predominantemente da Comunicação. Essa primeira identificação confirma que as redes de colaboração são mais robustas na área de Ciências da Informação. Para cada grupo foram identificadas as áreas de atuação e de formação dos dez pesquisadores com maior grau de conexão indegree. Os resultados estão sistematizados na Tabela 1, e os dados indicam que o componente fundamental que agrega os pesquisadores é a instituição e apenas marginalmente o tema da pesquisa. 
Tabela 1 - Composição de 10 grupos identificados pela modularidade. $O$ vínculo institucional entre pesquisadores predomina em detrimento da composição em torno de temas de pesquisa.

\begin{tabular}{|c|c|c|c|}
\hline Grupo & Nos & Subarea & Fator predominante para conexao \\
\hline Grupo 1 & 59 & Informaçào & Instituiçào (UFMG) \\
\hline Grupo 2 & 56 & Informaçào & Instituiçao (UnB) e Tema (estatistica e demografla) \\
\hline Grupo 3 & 46 & Comunicasalo & Instituiçao (UFMG) \\
\hline Grupo 4 & 40 & Informaçầo & Tema de pesiguika \\
\hline Grupo 5 & 37 & Informaçào & Geografla (regiao Sudeste) e Tema (biblioteconomia) \\
\hline Grupo 6 & 35 & Com. \& info. & Instituiçao (UFRGS) e Tema de pesquisa (Cibercultura) \\
\hline Grupo 7 & 33 & Informaçào & Instituiçà (UFSC) e Tema de pesquisa \\
\hline Grupo 8 & 29 & Informaçầo & Instituiçào (UNFSP) e Tema (informaçâo e tecnologia) \\
\hline Grupo 9 & 28 & Intormaçăo & Instituição (UFR) e Tema de pesquisa (Memoria) \\
\hline Grupo 10 & 23 & Comunicaça & Geografla (Sudeste e Nordeste) e Tema (Com. Digital) \\
\hline
\end{tabular}

Fonte: Os autores

\section{A Subárea da Comunicação}

Por fim, analisamos os três principais grupos na subárea da Comunicação que incluem as subcomunidades com maior índice de coautorias registradas na Plataforma Lattes. O Grupo 3 é constituído por 46 pesquisadores. Dentre os 10 usuários com maior indegree, oito são docentes ou tiveram passagem pelo PPG em Comunicação Social da UFMG, outro indício da vinculação institucional entre os pesquisadores. Dentre os usuários com maior grau de intermediação, dois são pesquisadores da UFMG e um terceiro atuou em parceria com essa instituição em projetos de pesquisa, servindo, portanto, de ponte para outros pesquisadores externos à UFMG. O Grupo 6 é constituído por 35 pesquisadores. Ele foi classificado como um grupo de natureza híbrida entre Informação e Comunicação por conter, dentre os pesquisadores com maior indegree, igual número de pesquisadores de cada subárea (cinco). Apesar da constituição híbrida, há uma clara vinculação institucional - dentre os 10 pesquisadores com maior indegree, 7 (sete) tiveram passagem pelo PPG em Comunicação e Informação da UFRGS, o que reforça o caráter híbrido entre Informação e Comunicação. As subredes dos Grupos 3, 6 e 10 podem ser vistas na Figura 6. 
Figura 6 - Detalhes dos três principais grupos relacionados com a subárea da Comunicação.

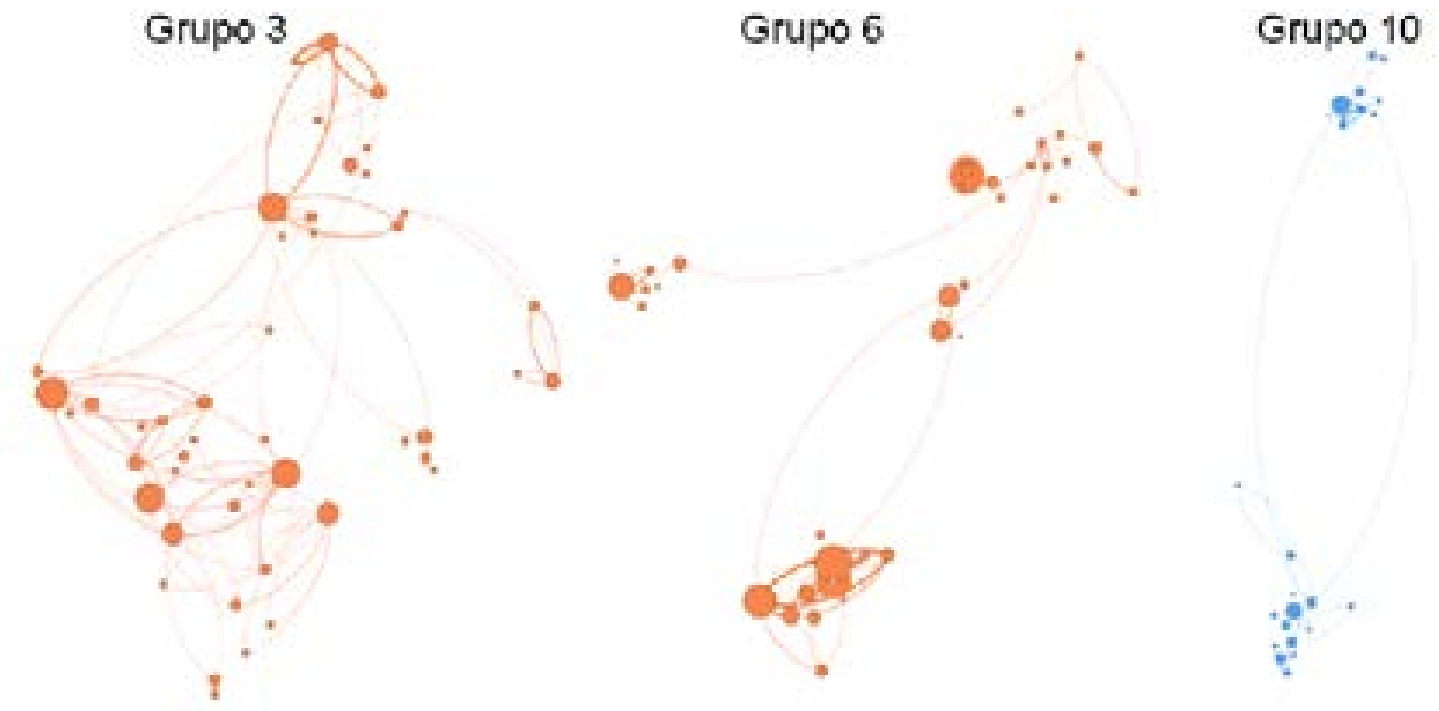

Fonte: Os autores

A constituição do Grupo 6 permite perceber a formação de três subgrupos de pesquisadores. O grupo superior corresponde a pesquisadores predominantemente dedicados à Cibercultura. Esse grupo está conectado por meio da vinculação institucional de alguns de seus membros que atuam ou são egressos do PPGCOM da UFRGS, além de pesquisadores da UFRGS da área de Ciências da Informação. Por fim, o terceiro grupo resulta de relações institucionais entre pesquisadores da UFBA, encabeçado por pesquisadores da área de Cibercultura que possuem relação de coautoria com o grupo localizado na porção superior do grafo. O Grupo 10, por sua vez, é composto por 23 pesquisadores e inclui dois grupos distintos geográfica e tematicamente, mas interconectados por um pesquisador que já atuou em coautoria com participantes dos dois subgrupos. A parte superior do grafo inclui pesquisadores da região Nordeste que atuam na área de jornalismo científico e a porção inferior inclui pesquisadores da região Sul que atuam na área de comunicação e jornalismo digital. 


\section{Conclusão}

Duas conclusões foram pontuadas ao longo deste trabalho. A primeira se refere à desproporção entre as redes de colaborações e coautorias das duas principais subáreas da CSAI, com pesquisadores da subárea das Ciências da Informação apresentando a esmagadora maioria das colaborações em comparação com pesquisadores da subárea Comunicação, cujas redes são usualmente esparsas e desconectadas. Há poucas pontes entre as duas subáreas, e as comunidades majoritariamente se formam ao redor de pequenos grupos ou pesquisadores individuais. Além disso, dentre os pesquisadores com maior número de colaborações e coautorias (grau), também há prevalência das Ciências da Informação. Esses dados põem em evidencia a fragilidade e incipiência da colaboração acadêmica na Comunicação, especialmente em comparação com as Ciências da Informação. Do mesmo modo, o alto número referente à distância média da rede como um todo $(8,545)$ evidencia um isolamento da produção e da colaboração em flagrante contraste com o cenário de pesquisa internacional (Newman, 2004).

Além disso, os resultados também indicam elevado grau de endogamia na subárea da Comunicação, uma vez que a cooperação ocorre predominantemente dentro de uma mesma instituição e apenas raramente em função da área de pesquisa. Ao invés de se aglutinar ao redor de objetos e eixos de pesquisa comuns, os pesquisadores aparecem agrupados ao redor de programas de pós-graduação, reforçando com isso as parcerias intrainstitucionais. Esse tipo de colaboração é possivelmente influenciado pelos critérios de avaliação dos programas de pós-graduação da CAPES, que atribui pontuações específicas para o índice de coautoria entre orientandos e orientadores. Esse diagnóstico se acentua em razão da relativa desconexão da rede de colaboração na subárea da Comunicação, que aparece mais isolada em comparação com as Ciências da Informação. De fato, a Comunicação compreende várias pequenas redes que funcionam como paróquias com forte associação a determinados programas institucionais. Embora esse diagnóstico se manifeste claramente na rede de coautorias, o mesmo padrão de colaboração também foi observado na rede de colaborações gerais.

Embora Comunicação e Ciências da Informação compartilhem uma origem comum (Stumpf e Weber, 2003), essas subáreas das ciências sociais aplicadas permanecem relativamente separadas, não obstante a existência de pesquisadores, conquanto em número reduzido, com alto grau de interconexão (Freeman, 1978) nas redes de colaboração e coautoria. Esses pesquisadores não apenas vinculam a pesquisa em comunicação e a pesquisa em informação e biblioteconomia, mas também estabelecem pontes estratégicas e 
interinstitucionais entre subáreas. Além disso, o perfil profissional desses pesquisadores indica a existência, embora incipiente, de um programa de pesquisa que confere organicidade à área e permite o vislumbre de um cenário em que grupos e paróquias colaborem mais intensamente uns com os outros.

É importante salientar as limitações do método e dos dados utilizados para estudar essas redes de colaboração na área de CSAI. Em primeiro lugar, conforme descrito na seção dedicada à metodologia, os dados empregados nessa análise se restringem a currículos com hyperlinks para outros currículos. Diversas colaborações, com isso, não aparecem registradas na base de dados analisada em razão da inexistência de links entre currículos (falha de preenchimento dos autores ou falha do próprio sistema Lattes). Do mesmo modo, também encontramos currículos com uma superpopulação de links para pesquisadores que não foram coautores ou colaboradores. Por fim, e em contraste com pesquisas anteriores realizadas com dados da Plataforma Lattes, empregamos nesse trabalho uma análise qualitativa das subáreas, uma vez que a identificação automática das subáreas e filiação dos pesquisadores não foi possível a partir da coleta automatizada e do parsing do XML.

As vantagens na utilização de bancos de dados digitais para a análise de colaborações acadêmicas se traduzem na possibilidade de identificar coautorias e colaborações de maneira relativamente simples, uma vez que as bases de dados podem ser convertidas para matrizes numéricas que servem de base para a construção dos grafos. Com isso, os dados podem ser observados sob a forma de redes, o que facilita a visualização da posição das instituições de pesquisa, dos próprios pesquisadores ou mesmo dos grupos de pesquisa que congregam pesquisadores. Consideramos, com isso, que não obstante as dificuldades em torno da extração, limpeza e processamento dos dados, os grafos fornecem indícios sólidos sobre as colaborações nas subáreas de pesquisa. Por fim, salientamos que em ambas as redes estudadas a incipiente área da Museologia não apresenta nenhuma métrica significativa de colaboração. A comunicação, por sua vez, embora estabelecida desde a década de 1970, ainda não adotou práticas de colaboração e coautoria que transcendam os limites impostos pelas instituições de ensino superior.

\section{Referências}

BALANCIERI, R. e outros. A análise de redes de colaboração científica sob as novas tecnologias de informação e comunicação: um estudo na Plataforma Lattes. Ciência da informação, v. 34, n. 1, 2005. Disponível em: <http://dx.doi. org/10.1590/S0100-19652005000100008> Acesso em: 10. fev. 2015. 
BARABÁSI, A.-L. e outros. Evolution of the social network of scientific collaborations. Physica A: Statistical Mechanics and its Applications, v. 311, n. 3, 2002.

BASTOS, M. T. Medium, Media, Mediação e Midiatização: A Perspectiva Germânica. In: MATTOS, M. Â e outros. Mediação e Midiatização. Salvador: EDUFUBA, v. 12, p. 53-77, 2012.

. Outcompeting Traditional Peers? Scholarly Social Networks and Academic Output. 48TH HAWAII INTERNATIONAL CONFERENCE ON SYSTEM SCIENCES, Kauai, Hawaii, US, 2015.

BULLINGER, A. C. et al. Towards Research Collaboration-a Taxonomy of Social Research Network Sites. AMCIS, p. 92, 2010.

CAPES. Documento da Área de 2009. Área de Avaliação: Ciências Sociais Aplicadas I. Brasília: CAPES, 2009.

Documento da Área de 2013. Área de Avaliação: Ciências Sociais Aplicadas I. Brasília: CAPES 2013.

CARRINGTON, P. J.; SCOTT, J.; WASSERMAN, S. Models and methods in social network analysis. Cambridge: Cambridge University Press, 2005.

CECHINEL, C. Scientific Collaboration between Countries. In: LACLO from a Social Network Analysis Perspective. Conferencias LACLO, 2013.

DA SILVA, A. K. A.; BARBOSA, R. R.; DUARTE, E. N. Rede social de coautoria em Ciência da Informação: estudo sobre a área temática de" Organização e Representação do Conhecimento". Informação \& Sociedade: Estudos, v. 22, n. 2, 2012.

DEGENNE, A.; FORSÉ, M. Introducing social networks. London: Sage, 1999.

DIGIAMPIETRI, L. e outros. Minerando e caracterizando dados de currículos Lattes. Brazilian Workshop on Social Network Analysis and Mining (BraSNAM), 2012.

Brax-ray: an x-ray of the brazilian computer science graduate programs. PLoS ONE, v. 9, n. 4, p. e94.541, 2014.

FIGUEIREDO, N. O ensino de biblioteconomia no Brasil: relatório de equipe de pesquisa sobre o status quo das escolas de biblioteconomia e documentação, com ênfase na situação do pessoal docente. Brasília: Ministo da Educaçâo e Cultura, 1978.

FREEMAN, L. C. Centrality in social networks conceptual clarification. Social Networks, v. 1, n. 3, p. 215-239, 1978.

GEWIN, V. Collaboration: Social networking seeks critical mass. Nature, v. 468, n. 7.326, p. 993-994, 2010. 
LANE, J. Let's make science metrics more scientific. Nature, v. 464, n. 7.288, p. 488-489, 2010.

LEYDESDORFF, L. Clusters and maps of science journals based on bi-connected graphs in Journal Citation Reports. Journal of Documentation, v. 60, n. 4, p. 371427, 2004a. Disponível em: <http://dx.doi.org/10.1108/00220410410548144> Acesso em: 10. fev. 2015.

. Top-down decomposition of the Journal Citation Reportof the Social Science Citation Index: Graph- and factor-analytical approaches. Scientometrics, v. 60, n. 2, p. 159-180, 2004b. Disponível em <http://dx.doi.org/10.1023/ B:SCIE.0000027678.31097.e0> Acesso em: 10. fev. 2015.

MAIA, M. D. F. S.; CAREGNATO, S. E. Co-autoria como indicador de redes de colaboração científica. Perspectivas em Ciência da Informação, v. 13, n. 2, p. 18-31, 2008. Disponível em: <http://dx.doi.org/10.1590/S1413-99362008000200003> Acesso em: 10. fev. 2015.

MARTINS, D. L.; FERREIRA, S. M. S. P. Análise dinâmica de redes sociais de coautoria: um estudo de caso a partir de múltiplos indicadores na área da ciências da comunicação. XIV Encontro Nacional de Pesquisa em Ciência da Informação (ENANCIB), 2014.

MENA-CHALCO, J. P. e outros. Brazilian bibliometric coauthorship networks. Journal of the Association for Information Science and Technology, v. 65, n. 7, p. 14241445, 2014. Disponível em: <http://dx.doi.org/10.1002/asi.23010> Acesso em: 10. fev. 2015.

MOODY, J. The Structure of a Social Science Collaboration Network: Disciplinary Cohesion from 1963 to 1999. American Sociological Review, v. 69, n. 2, p. 213238, 2004. Disponível em: <http://dx.doi.org/10.1177/000312240406900204> Acesso em: 10. fev. 2015.

NEWMAN, M. E. J. The structure of scientific collaboration networks. Proceedings of the National Academy of Sciences, v. 98, n. 2, p. 404-409, 2001. Disponível em: <http://dx.doi.org/10.1073/pnas.98.2.404> Acesso em: 10. fev. 2015.

. Coauthorship networks and patterns of scientific collaboration. Proceedings of the National Academy of Sciences, v. 101, n. suppl 1, p. 5.200-5.205, 2004. Disponível em: < http://dx.doi.org/10.1073/pnas.0307545100> Acesso em: 10. fev. 2015.

ORTEGA, C. D. Surgimento e consolidação da Documentação: subsídios para compreensão da história da Ciência da Informação no Brasil. Perspectivas em Ciência da Informação, v. 14, n. 3, p. 59-79, 2009. Disponível em: <http:// dx.doi.org/10.1590/S1413-99362009000400005> Acesso em: 10. fev. 2015. 
OTTE, E.; ROUSSEAU, R. Social network analysis: a powerful strategy, also for the information sciences. Journal of information Science, v. 28, n. 6, p. 441-453, 2002. Disponível em: <http://dx.doi.org/10.1177/016555150202800601> Acesso em: 10. fev. 2015.

PRIMO, A.; STUMPF, I.; CONSONI, G. Análise de citações dos trabalhos da Compós 2008. E-Compós, v. 11, n. 3, 2008.

RECUERO, R. Redes sociais na internet. Porto Alegre: Sulina, 2009.

ROMANCINI, R. Periódicos brasileiros em Comunicação: histórico e análise preliminar. Verso e Reverso, v. 18, n. 39, 2004.

STUMPF, I. R.; WEBER, M. H. Comunicação e informação: conflitos e convergências. In: LOPES, M. I. V. D. (Ed.). Epistemologia da Comunicação. São Paulo: Loyola, p. 121-134, 2003.

WAGNER, C. S.; LEYDESDORFF, L. Network structure, self-organization, and the growth of international collaboration in science. Research Policy, v. 34, n. 10, p. 1.6081.618, 2005. Disponível em: <http://dx.doi.org/10.1016/j.respol.2005.08.002> Acesso em: 10. fev. 2015.

WASSERMAN, S.; FAUST, K. Social Network Analysis. Cambridge: Cambridge University Press, 1994.

Recebido em : 31/7/2015

Aceito em : 25/8/2015

Endereço dos autores

Marco T. Bastos <mtabastos@gmail.com>

Universidade de São Paulo, Escola de Comunicações e Artes, Departamento de Jornalismo e Editoração.

Av. Prof. Lúcio Martins Rodrigues, 443 - Bloco A, sala 41. Cidade Universitária, São Paulo. Butantã

05508-900 - Sao Paulo, SP - Brasil

Telefone: (11) 30914058

Gabriela Zago <gabrielaz@gmail.com>

Universidade Federal de Pelotas, Unidades e Cursos de Graduação, Centro de Artes.

Rua Coronel Alberto Rosa, 62 - Centro

96010770 - Pelotas, RS - Brasil

Raquel Recuero <raquelrecuero@gmail.com>

Universidade Católica de Pelotas, Centro de Ciências Humanas e da Educação, Departamento de Letras.

Felix da Cunha, 412 - Centro

96010-000 - Pelotas, RS - Brasil

Telefone: (53) 32848111 